IZA DP No. 4853

Racial and Ethnic Disparities in the Use of Drug Therapy

John R. Bowblis

Myeong-Su Yun

March 2010 


\title{
Racial and Ethnic Disparities in the Use of Drug Therapy
}

\author{
John R. Bowblis \\ Miami University \\ Myeong-Su Yun \\ Tulane University \\ and IZA
}

Discussion Paper No. 4853

March 2010

IZA

P.O. Box 7240

53072 Bonn

Germany

Phone: +49-228-3894-0

Fax: +49-228-3894-180

E-mail: iza@iza.org

\begin{abstract}
Any opinions expressed here are those of the author(s) and not those of IZA. Research published in this series may include views on policy, but the institute itself takes no institutional policy positions.

The Institute for the Study of Labor (IZA) in Bonn is a local and virtual international research center and a place of communication between science, politics and business. IZA is an independent nonprofit organization supported by Deutsche Post Foundation. The center is associated with the University of Bonn and offers a stimulating research environment through its international network, workshops and conferences, data service, project support, research visits and doctoral program. IZA engages in (i) original and internationally competitive research in all fields of labor economics, (ii) development of policy concepts, and (iii) dissemination of research results and concepts to the interested public.
\end{abstract}

IZA Discussion Papers often represent preliminary work and are circulated to encourage discussion. Citation of such a paper should account for its provisional character. A revised version may be available directly from the author. 
IZA Discussion Paper No. 4853

March 2010

\section{ABSTRACT}

\section{Racial and Ethnic Disparities in the Use of Drug Therapy*}

The purpose of this research is to explain the variation in the utilization of drug therapy for the medical conditions of depression, high cholesterol, and hypertension between Hispanics, non-Hispanic blacks, and non-Hispanics whites using Oaxaca-type decomposition analysis based on logit estimates. We find that almost the entire share of the utilization differences in drug therapy between blacks and whites can be explained by the differences in the coefficients of observable characteristics, while the sources of the utilization difference between the whites and Hispanics are split between the differences in the observable characteristics and the coefficient estimates. This result implies that strategies to improve racial and ethnic disparities need to be tailored to each group by focusing on the specific factors that are attributed to causing the disparity.

JEL Classification: I11, I12

Keywords: racial and ethnic disparities, drug therapy, depression, high cholesterol, hypertension, Oaxaca decomposition

Corresponding author:

Myeong-Su Yun

Department of Economics

Tulane University

206 Tilton Hall

6823 St. Charles Ave.

New Orleans, LA 70118

USA

E-mail: msyun@tulane.edu

\footnotetext{
* We would like to thank the editor and two anonymous referees for helpful comments.
} 


\section{Introduction}

The existence of racial and ethnic disparities in healthcare has been widely reported (e.g., Trivedi et. al, 2005). Variations in the access and utilization of drug therapy for chronic conditions by race/ethnicity can lead to significant health outcomes differences and higher health care costs. These disparities are of significant policy concern because public sources pay for a substantial portion of health care costs. This has led to a call to study the existence of disparities and identify potential areas in which intervention strategies can be developed (see Smedley et al, 2003; Anderson et al, 2004; National Research Council, 2004). Although many studies have confirmed the existence of racial/ethnic disparities (Agency for Healthcare Research and Quality, 2005; Jha et al, 2005; Trivedi et al, 2005; Han and Liu, 2005), the causes of disparities in the use of drug therapy remains understudied.

Multiple studies have documented the size of the racial/ethnic disparity in the use of prescription drugs, with most studies comparing the outcomes of the Hispanic and non-Hispanic black populations to the outcomes of the non-Hispanic white population. ${ }^{1}$ Schore, Brown, and Lavin (2004) examined the number of prescription drugs used by racial/ethnic groups among individuals that are dually eligible for Medicare and Medicaid. They found statistically significant differences in the use of prescription drugs, with blacks filling 0.8 fewer prescriptions per month than whites. Although there is variation in the use of prescription drugs, differences in total number of prescriptions filled do not necessarily prove the existence of a disparity if the underlying need for prescription drugs are different.

By studying disparities in the receipt of drugs for specific medical conditions, Schneider, Zaslavsky, and Epstein (2002) found blacks were less likely than whites to receive a beta-blocker

\footnotetext{
${ }^{1}$ Throughout the paper the word "non-Hispanic" has been omitted when referring to non-Hispanic blacks and nonHispanic whites
} 
after a heart attack. For Medicare beneficiaries with diabetes, heart disease, and hypertension, Briesacher, Limcangco, and Gaskin (2004) examined differences in the receipt and amount spent on prescription drugs. They compared people with similar Medicare supplemental insurance and found statistically significant differences in the use of prescription drugs by race/ethnicity for aggregate use and for specific medical conditions. Similarly, Han and Lui (2005) found disparities in the use of mental illness drugs among people with self-reported mental illnesses and Gonález et al. (2008) found that difference in the percentage of black patients with major depressive disorder that use an antidepressant is 22.7 percentage points lower than for whites.

A significant number of papers showing the existence of racial/ethnic disparities rely on statistical models which include a binary indicator for race/ethnicity as an explanatory variable in addition to other controlling factors. This method allows for verification of the existence of a disparity but constrains the coefficient estimates for these other factors to be the same across groups. That is, this method overlooks the possibility that socio-economic attributes may differently contribute to the decision of whether or not to adhere to drug therapy by groups. It has long been understood that racial/ethnic status impacts health outcomes, but these effects interact with the socioeconomic status of the individual. For example, research on infant and mortality rates by racial/ethnic groups has found that Hispanics generally have better health outcomes than blacks even though they have similar socioeconomic status (Palloni and Morenoff, 2001; Palloni and Arias, 2004; Markides and Eschbach, 2005; Hummer et al., 2007). When studying the sources of the disparity, it can be better understood by separating the disparity into two effects using Oaxaca-type decomposition based on separate estimates for each group: the characteristics effect and the coefficients effect (see Oaxaca (1973) for explanation of the two effects). 
The characteristics effect measures how differences in the characteristics of each group affect the difference in the dependent variable. For example, suppose that younger individuals with depression are less likely to use an antidepressant. If whites are older than Hispanics on average, the characteristics effect would explain how much of the difference in utilization between whites and Hispanics of antidepressants is due to differences in age composition. In contrast, the coefficients effect measures the impact of variation in the parameter estimates on differences in utilization when separate regressions are estimated for each group. Suppose that white males are more likely to receive hypertensive drugs than black males, even though both have the same characteristics. Then the coefficients effect measures the contribution of the difference in the two coefficient estimates to the overall difference in the hypertension drug utilization by the two groups. $^{2}$

Recently, the use of Oaxaca decomposition has increased in popularity for studying disparities, particularly in the health care literature. Decomposition analysis has been used to study racial/ethnic disparities in access to health insurance (Pylypchuk and Selden, 2008; Zuvekas and Taliaferro, 2003; Thomasson, 2006), ${ }^{3}$ while a study by Jacobson et al. (2007) used Oaxaca decomposition to study the completion of substance abuse treatment programs. Although the technique has gained in popularity, it has not been extensively used to study drug therapy.

In this paper, we investigate the sources of the variation in prescription drug therapy use rates for three groups, non-Hispanic whites, non-Hispanic blacks, and Hispanics, using a straightforward Oaxaca-type decomposition method based on non-linear estimation (Yun, 2004). One nice feature of the employed decomposition method is that it enables us to measure the

\footnotetext{
${ }^{2}$ The variation of coefficients by group may be arisen by several causes such as differences in behavior and discrimination.

${ }^{3}$ See Mayberry et al (2000) and Weineck et al (2000) for a discussion of disparities in health insurance coverage.
} 
magnitude of the characteristics and coefficients effects of individual factors. This in turn allows public policy makers to identify target variables whose values and effects are contributing to racial/ethnic disparities, and to devise policies to reduce discrepancies in modifiable characteristics.

We focus on the receipt of prescription drugs for depression, high cholesterol, and high blood pressure, also known as hypertension, using samples from the Medical Expenditures Panel Survey (MEPS). ${ }^{4}$ These diseases are prevalent in the United States, have clear pharmacological practice guidelines, and have significant mortality and quality of life implications. For example, depression is the fourth leading cause of non-fatal disease burden (Üstün et al, 2004) and the standard pharmaceutical treatment for depression is antidepressants. ${ }^{5}$ In contrast, high cholesterol and high blood pressure are two of the main risk factors for heart disease (Kaiser Family Foundation, 2007) and also have standard drug treatment guidelines. ${ }^{6}$ Further, mismanagement of these conditions due to failure to adhere to the drug therapy can lead to increased health care costs in the future.

We study various medical conditions as robustness checks, which allow us to determine if disparities are similar or different across medical conditions and to determine if intervention strategies to reduce disparities would be effective across various drug treatments. Our results

\footnotetext{
${ }^{4}$ We focus on the racial and ethnic gaps in the receipt of antidepressant drug therapy for depression while studying the receipt of drugs for high cholesterol and high blood pressure to determine if disparities follow similar patterns for other medical conditions.

${ }^{5}$ The treatment guidelines are available in Practice Guidelines for Treatment of patients with major depressive disorder, second edition (http://www.psychiatryonline.com/pracGuide/loadGuidelinePdf.aspx?file=MDD2e 05-15$\frac{06)}{6}$.

${ }^{6}$ The treatment guidelines for high cholesterol are available in Third report of the expert panel on detection, evaluation, and treatment of high blood cholesterol in adults (adult treatment panel III) executive summary (http://www.nhlbi.nih.gov/guidelines/cholesterol/atp3xsum.pdf). Standard pharmacological treatment includes the use of statins, such as Lipitor or Zocor. Treatment guidelines for high blood pressure are available in Seventh Report of the Joint National Committee on Prevention, Detection, Evaluation, and Treatment of High Blood Pressure (JNC 7) Express (http://www.nhlbi.nih.gov/guidelines/hypertension/express.pdf). Standard pharmacological treatment includes the use of a beta-blocker and/or angiotensin-converting enzyme (ACE) inhibitor or its close cousin the angiotensin II receptor blocker (ARB). In the analysis, receipt of a hypertensive drug is defined as obtaining either a beta-blocker or ACE/ARB.
} 
suggest that almost the entire share of the utilization differences in drug therapy between blacks and whites can be explained by the differences in the coefficients of observable characteristics. Policy should focus on educating blacks of the danger of not adhering to the drug therapy since blacks and whites with similar characteristics, even with the same education and insurance coverage, behave significantly different. In contrast, the utilization differences between the whites and Hispanics are caused by both differences in the observable characteristics and differences in the coefficient estimates. Public policy makers should pay attention to providing Hispanics with better insurance coverage and improving schooling attainment in order to reduce the disparity.

\section{Data}

The 2002 Medical Expenditures Panel Survey (MEPS) is the data source used to analyze the racial/ethnic disparities in the use of prescription drugs for three common medical conditions. We created three mutually-exclusive racial and ethnic groups as recommended by minority health task groups to identify Hispanic Americans independently of race: non-Hispanic whites, non-Hispanic blacks, and Hispanics (Zambrana and Carter-Pokras, 2001). ${ }^{7}$ The sample for each medical condition is constructed from people over the age of 18 that have an affirmative response to the self-reported question of being told by a doctor they had the specific medical condition in the last year. For example, this means the depression sample consists of individuals over the age of 18 that have self-reported being told by a doctor they have depression. ${ }^{8}$ Once each sample is identified, the prescription medicine event file is used to determine if the

\footnotetext{
${ }^{7}$ Although there is significant heterogeneity within racial and ethnic groups, MEPS does not provide the specificity to identify racial and ethnic subgroups.

${ }^{8}$ This definition eliminates the use of the drug therapies for other indications or off-label uses. For example, a person who takes antidepressant for smoking cessation or anxiety would not be included in the sample.
} 
individual received any prescription drug for the medical condition from a list of brand and generic names for antidepressants, statins, and hypertensive drugs. An individual is determined to receive drug treatment if they received any drug in the drug class.

Table 1 reports the proportion of people that received drug treatment for each condition, broken down by race/ethnicity. Depressed blacks and Hispanics are less likely to fill an antidepressant than depressed whites. The difference in the proportion of whites and blacks that received an antidepressant is 16.7 percentage points, while the difference between whites and Hispanics is 21.5 percentage points. Disparities are also found in individuals diagnosed with high cholesterol. The difference in the proportion of people with high cholesterol that received a statin is 4.0 percentage points between blacks and whites and 14.3 percentage points between Hispanics and whites. On the other hand, the disparity relative to whites is larger for blacks than Hispanics in the use of hypertensive drugs for those diagnosed with high blood pressure. The unadjusted difference between white and black use of hypertensive is 14.7 percentage points, while the difference is only 4.9 percentage points for Hispanics and whites.

\section{<INSERT TABLE 1>}

In addition to the race/ethnicity factor, other factors which determine pharmacological utilization are divided into six groups: demographic characteristics, education, income, obesity, health status and insurance, and location. The demographic characteristics used in the regression are age, gender, and marital status. Higher socio-economic status is positively correlated with adherence to physician's orders and health outcomes. Socio-economic status is measured by income and education, which is classified into below high school degree, high school degree, and at least some college. 
Besides demographics and socio-economic status, the health status of an individual could influence the use of medications. First, obesity is known to increase the risk of heart disease and is associated with depression. To measure obesity, body mass index (BMI) is used to classify people into normal, overweight (BMI 25.0-29.9), and obese (BMI $\geq 30.0)$ weight groups. Second, self-reported health status is used to measure the perceived health status. People who perceive their health to be poor may be more likely to use drug therapy to improve their health. Two self-reported health variables are used: poor physical health and poor mental health. ${ }^{9}$ For each variable, an individual is classified as being in poor health if they did not report their health status as "good" or "excellent". The final measure of health status used is the number of heart disease conditions. Each individual self-reports if they have a history of high blood pressure, coronary artery disease, angina, and heart attack. This measure is constructed from summing over the number of affirmative responses. ${ }^{10}$ Recently, it is suggested that there may be a link between heart disease and depression (Zellweger et al, 2004).

The final two factors that could influence drug utilization are health insurance coverage and regional variation. Insurance facilitates access to care by lowering the out-of-pocket cost to see a physician and purchase prescription drugs. Although health insurance has been shown to improve health outcomes, the quality of health insurance coverage varies significantly in terms of premium cost, breath of services and providers covered, and cost-sharing. For example, Medicaid is insurance that covers the poor. One concern with Medicaid is that it reimburses physicians at low rates. This causes many physicians to either not accept Medicaid or locate into neighborhoods that have fewer Medicaid recipients. If Medicaid disproportionally covers one racial or ethnic group, this could lead to disparities. To capture differences in insurance

\footnotetext{
${ }^{9}$ Self-reported mental health status is only used in the regression analysis for the depression sample.

${ }^{10}$ In the case of the hypertension sample, hypertension is excluded in the calculation of the number of heart disease conditions.
} 
coverage, indicator variables are created for coverage by Medicare, Medicaid, and private insurance, during the year. Finally, there may be regional variation in the use of health care. Regional variation is captured through indicator variables for living in a metropolitan statistical area and region of the country: Northeast, Midwest, South, and West.

For brevity, we only report the sample statistics for the depression sample (Table 2). The patterns tended to be similar for the high cholesterol and hypertension samples across race/ethnicity. Whites tend to be male, older, and have higher incomes and education levels than blacks and Hispanics. Further, whites are less likely to be overweight or obese and are less likely to report poor health status than minorities. There is also significant variation in the rates of coverage by health insurance. Nearly seventy percent of whites have private insurance, $23.3 \%$ have Medicare, and $16.9 \%$ have Medicaid. Blacks and Hispanics are less likely to have Medicare or private insurance. In fact, fewer than forty percent of blacks and Hispanics have private insurance, but $44.9 \%$ of blacks and $35.5 \%$ of Hispanics have Medicaid. The social insurance program of Medicaid covers more blacks and Hispanics compared to the general population and the low reimbursement rates associated with the program may explain some of the disparity between whites and minorities.

\section{$<$ INSERT TABLE 2>}

\section{Estimation}

Typically, disparities between groups are identified by regressing the outcome of interest against racial/ethnicity indicator variables and other covariates (so-called treatment effect model). A statistically significant coefficient for the race/ethnicity variables indicates there may be a disparity. We first follow this strategy by estimating logit models with a binary variable of the 
use of a prescription drug in the drug class as the dependent variable for each medical condition sample.

Although estimation of the logit regression for the treatment effects model will identify the existence of differences in the outcome by group after controlling other factors, the method constrains the coefficient estimates for these other factors to be the same across race/ethnicity. Alternatively, we may estimate separate regressions for each group, which allows the coefficients to vary by group but complicates interpretation of the size and cause of the disparities. Based on the regressions for each group, an Oaxaca-type decomposition is used to account for gaps in drug use. This allows us to separate the disparity into two separate effects: the characteristics effect due to differences in covariate composition and the coefficients effect due to differences in effects of covariates, i.e., logit coefficients.

We implement Oaxaca-type decomposition equations for discrete dependent variables as suggested by Yun (2004). Previously, the difference in the mean value of a binary dependent variable was decomposed by so-called "simulation" (see Abowd and Killingsworth 1984; Fairlie 2005). For example, discrete choice models are estimated for each group, and one groups' coefficients substituted with those of the other group in order to calculate a counter-factual predicted probability. The coefficients effect equals the difference between the counter-factual prediction and the observed probability for the former group, holding characteristics constant. This simulation method suffers from several limitations. Not only is it tedious but also problematic because it may be sensitive to the order of the switching (see Ham, Svejnar and Terrell 1998, p. 1137 for a discussion of path-dependency). Yun (2004) proposes a decomposition method that provides a systematic treatment for differences in binary outcomes 
that is free of path dependency. ${ }^{11}$

As discussed above, we estimate logit models of drug therapy for each race/ethnicity separately, where the dependent variable has a value of one if the patient received a treatment and the sample is restricted to patients that self-reported having the specific medical condition. Formally, we assume that there is a latent variable of receiving drug therapy which is specified as follows suppressing a racial/ethnic subscript, $T_{i}^{*}=X_{i} \beta+u_{i}$, where $X_{i}$ is a $1 \times K$ vector of independent variables, $\beta$ is a $K \times 1$ vector of coefficients. What we observe is a dummy variable $T_{i}$, whose value is one if $T_{i}^{*}>0$ and zero otherwise. The likelihood of receiving drug therapy for patient $i(T=1)$ is estimated by $F\left(X_{i} \beta\right)$, where $F$ is the logistic distribution function, that is, $F\left(X_{i} \beta\right)=1 /\left[1+\exp \left(-X_{i} \beta\right)\right]$. The observed drug therapy rate is equal to the sample average of the patient's drug therapy likelihood, or $\bar{T}=\overline{F(X \beta)}=\frac{1}{N} \sum_{i=1}^{N} F\left(X_{i} \beta\right)$. Algebraically, the differences in the average likelihood of drug therapy between whites (group $A$ ) and blacks/Hispanics (group $B$ ) may be decomposed as following:

$$
\bar{T}_{A}-\bar{T}_{B}=\left[\overline{F\left(X_{A} \beta_{A}\right)}-\overline{F\left(X_{B} \beta_{A}\right)}\right]+\left[\overline{F\left(X_{B} \beta_{A}\right)}-\overline{F\left(X_{B} \beta_{B}\right)}\right]
$$

where the first and the second components in the right hand side represent the characteristics effect and coefficients effect, and the "over bar" represents the value of the sample's average.

The above decomposition gives us the overall coefficients and characteristics effects. To find the relative contribution of each variable to the treatment gap, in terms of characteristics and

\footnotetext{
${ }^{11}$ What Yun (2004) proposed is a general method to decompose differences in the first moment for nonlinear models which have already been applied to count-data model (Park and Lohr, 2008) and hazard rate model (Powers and Yun, 2009) in addition to probit/logit models. See Pylypchuk and Selden (2008) for pros and cons of existing Oaxaca-type decomposition methods for non-linear models.
} 
coefficients effects, we employ a decomposition equation proposed by Yun (2004); ${ }^{12}$

$$
\bar{T}_{A}-\bar{T}_{B}=\sum_{k=1}^{K} W_{\Delta X}^{k}\left[\overline{F\left(X_{A} \beta_{A}\right)}-\overline{F\left(X_{B} \beta_{A}\right)}\right]+\sum_{k=1}^{K} W_{\Delta \beta}^{k}\left[\overline{F\left(X_{B} \beta_{A}\right)}-\overline{F\left(X_{B} \beta_{B}\right)}\right],
$$

where

$$
W_{\Delta X}^{k}=\frac{\left(\bar{X}_{A}^{k}-\bar{X}_{B}^{k}\right) \beta_{A}^{k}}{\left(\bar{X}_{A}-\bar{X}_{B}\right) \beta_{A}}, W_{\Delta \beta}^{k}=\frac{\bar{X}_{B}^{k}\left(\beta_{A}^{k}-\beta_{B}^{k}\right)}{\bar{X}_{B}\left(\beta_{A}-\beta_{B}\right)} \text {, and } \sum_{k=1}^{K} W_{\Delta X}^{k}=\sum_{k=1}^{K} W_{\Delta \beta}^{k}=1,
$$

where $\bar{X}_{A}^{k}$ and $\bar{X}_{B}^{k}$ are average values of explanatory variables $k$ for groups $A$ and $B$, respectively. ${ }^{13}$

\section{Results}

In the receipt of antidepressants, both blacks and Hispanics have lower treatment rates relative to whites conditional on having depression (Table 1). Logit regressions are used to identify which factors predict the use of antidepressants among those diagnosed with depression (Table 3). The first two columns of the table report the estimated coefficients and marginal effects for the pooled sample, while the remaining columns report the results for each

\footnotetext{
${ }^{12}$ In order to obtain a proper weight, the following approximations are used; first, an approximation of the value of the average of the function, $\overline{F(X \beta)}$, with that of the function evaluated at the average value of exogenous variables, $F(\bar{X} \beta)$; second, a first order Taylor expansion to linearize the characteristics and coefficients effects around $\bar{X}_{A} \beta_{A}$ and $\bar{X}_{B} \beta_{B}$. See Yun (2004) for details.

${ }^{13}$ For computing asymptotic standard errors of the characteristics and coefficients effects, see Yun (2005a). We deal with robustness issues, known as the index or parameterization problem and the identification problem in detailed decompositions. A decomposition equation with a different parameterization, that

is, $\left[\overline{\Phi\left(X_{A} \beta_{B}\right)}-\overline{\Phi\left(X_{B} \beta_{B}\right)}\right]+\left[\overline{\Phi\left(X_{A} \beta_{A}\right)}-\overline{\Phi\left(X_{A} \beta_{B}\right)}\right]$, is possible; our results with it are not substantially different from those presented here and are available from the authors upon request. Another issue when interpreting the decomposition results is that the coefficients effect in the detailed decomposition is not invariant to the choice of omitted groups when dummy variables are used (see Oaxaca and Ransom 1999, for details of this issue). We follow a solution suggested by Yun $(2005 \mathrm{~b}, 2008)$ that, if alternative reference groups yield different estimates of the coefficients effects for each individual variable, it is natural to obtain estimates of the coefficients effects for every possible specification of the reference groups and take the average of the estimates of the coefficients effects with various reference groups as the "true" contributions of individual variables to differentials. While appearing cumbersome, this can be accomplished with a single estimation. We can transform our logit estimates into a normalized equation and use the normalized equation for our decomposition.
} 
racial/ethnic group. For the pooled regression, even after controlling for observable factors, the disparity is found to exist for both blacks and Hispanics. Consistent with the pattern found by Han and Lui (2005), the percentage of blacks that use antidepressants is 18.7 percentage points lower than whites, while the difference is 14.9 percentage points for Hispanics compared to whites. Being older and female increased the chance of receiving an antidepressant. Two other factors that increase the probability are obesity and having a higher level of education. Insurance is an important factor in determining antidepressant use.

\section{<INSERT TABLE 3>}

Comparing the white sample to black sample regressions, there is some significant variation in the size and direction of the coefficient estimates, particularly for the variables of education, obesity, and health insurance. While whites with some college education are 8.5 percentage points more likely to use an antidepressant than whites with a high school education, for blacks some college reduced the chance of using an antidepressant by 32.6 percentage points. For those without a high school education, whites are four percentage points less likely to use an antidepressant than whites with a high school degree. In contrast, blacks without a high school education are 3.5 percentage points more likely to use an antidepressant than those with a high school education, but the effect of not having a high school degree is not statistically significant for both groups. Obesity is found to increase the probability of using an antidepressant in both groups, but the effect is four times larger for blacks than for whites. Finally, having Medicare increased the probability of using a drug for both groups, but blacks are over 49.3 percent more likely to use a drug if they have Medicare.

Hispanics had coefficient estimates that are more comparable to whites than blacks except in three cases. First, the effect of being a male Hispanic is larger than for white males. 
White males are 8.9 percent less likely to obtain an antidepressant than white females, but for Hispanics the effect is a 14.9 percent reduction. Second, Hispanics with below a high school education are less likely to use antidepressants than whites with similar education. Hispanics without a high school degree are 14.1 percent less likely to use antidepressants than Hispanics with a high school education. This compares to whites without a high school education only being 4 percent less likely to use antidepressants than whites with a high school degree. Finally, Hispanics that self-report poor physical and mental health status have higher odds of using an antidepressant than Hispanics that do not report poor health status. Whites are about three percent more likely to use antidepressants if they reported poor physical or mental health compared to whites that do not report poor health status, but both results are insignificant. Compared to Hispanics that do not report poor health status, Hispanics that reported poor physical health are 13.2 percent more likely to use an antidepressant, while Hispanics that reported poor mental health are 32 percent more likely to use an antidepressant. This variation in the effect of health status between white and Hispanics could be due to differences in the manifestation of the symptoms of depression, the level of severity of depression before treatment is sought, or differences in self-reported measures of health (Myers et al., 2002).

The comparison of the average characteristics and the coefficient estimates in Tables 2 and 3 find there is significant variation by racial/ethnic group. The decomposition results between whites and blacks and between whites and Hispanics are presented in Table 4. The first row decomposes the aggregate disparity into the characteristics and coefficients effects. The aggregate effect for blacks compared to whites find that $97.5 \%$ of the disparity in the use of antidepressants between the two groups can be explained by differences in their coefficients, while only $2.5 \%$ of the disparity is explained by differences in their characteristics. This means 
that if blacks had the same coefficient estimates as whites, then 16.3 percentage points of the 16.7 percentage point difference between black and white utilization of antidepressants among those reporting being diagnosed with depression would not exist. This has important consequences for reducing the disparity in the use of antidepressants between whites and blacks. Although blacks on average have lower socio-economic status and less generous insurance coverage than whites, the source of the disparity is not the differences in the characteristics but how the characteristics affect the rate of use compared to whites.

To further understand which characteristics and coefficients are different, the aggregate effect is broken down into sub-aggregate effects. This allows for identification of which group of variables are driving the variation. The disparity in antidepressant use between depressed whites and depressed blacks is almost entirely explained by the coefficients effect and, as expected, none of the sub-aggregate characteristics effects are statistically significant. The subaggregate coefficients effects of education and income are negative and statistically significant. These results suggest that if the effect of education and income were the same for blacks as whites, then the disparity would be larger. In fact, if blacks with similar education as whites had the same coefficients as whites, the disparity would increase by 8.9 percentage points. In the case of the sub-aggregate effects of health status including obesity and insurance variables, the coefficients effects are positive and statistically significant. This means behavior by blacks and whites towards antidepressants is different even if they have similar insurance coverage. For example, depressed blacks with Medicare are fifty percent more likely to receive an antidepressant, but the effect for depressed whites with Medicare is only five percent. This suggests that blacks and whites that are not on Medicare have significantly different access to antidepressants. Therefore, if blacks have similar coefficients as whites for health variables, the 
disparity would decrease by 18.8 percentage points, causing depressed blacks to use more antidepressants than depressed whites. These results suggest that blacks and whites with similar levels of education and insurance coverage have significantly different rates of antidepressant use and efforts to reduce the disparity need to focus on why the two groups behave substantially different.

\section{<INSERT TABLE 4>}

In contrast, the aggregate difference in the proportion that used antidepressants between whites and Hispanics was 21.5 percentage points. Of this difference, $32.7 \%$ is explained by the characteristics effect and $67.3 \%$ is explained by the coefficients effect. Both are statistically significant at the $1 \%$ level. This suggests that although the majority of the differences between Hispanics and whites are due to their coefficients, about one-third of the disparity is associated with differences in the characteristics of depressed Hispanics and depressed whites. This is in contrast to the disparity between whites and blacks which is almost exclusively explained by coefficients effect. Consequentially, this means that attempts to improve disparities between Hispanics and whites need to focus on why Hispanics have different rates of use as whites with similar characteristics, as well as eliminating differences in the average characteristics of Hispanics and whites. This later effort to eliminate differences in the average characteristics may be harder if those differences are not modifiable (i.e. age or gender).

In the case of depressed Hispanics compared to depressed whites, the aggregate effect suggests that majority of the disparity can be explained by the coefficients effect. Nonetheless, the only sub-aggregate coefficients effect found to be statistically significant is obesity. Obese Hispanics are 1.7 percentage points more likely to receive an antidepressant than obese whites. If Hispanics had the same coefficient for obesity as whites, sixty-two percent of the disparity 
between whites and Hispanics would disappear. Therefore, same as the case for the difference between blacks and whites, interventions to reduce the disparity between Hispanics and whites need to focus on why obesity impacts the use of antidepressants differently for each group.

However, unlike the case for the blacks and whites, we also have to pay attention to the difference in characteristics between Hispanics and whites since one-third of the disparity is explained by the characteristics effect. When we break down the overall effect into subaggregate level, there are four sub-aggregate characteristics effects that are statistically significant. Depressed Hispanics tend to be younger, female, and are less likely to have a high school or college degree. If Hispanics have similar demographic characteristics as whites then the disparity between the two groups would be reduced by slightly less than one percent point, while if Hispanics had similar education levels as whites, then the disparity would be 2.7 percentage points smaller. Both results are marginally significant. Further, Hispanics are more likely to be uninsured or on Medicaid, and report poor health than their white counterparts. If differences in reported health status and insurance coverage would disappear, then the disparity between whites and Hispanics would be 2.7 percentage points smaller. Further, Hispanics and whites have different regional distributions, which account for 2 percentage points of the disparity. Although the characteristics effect only explains one-third of the disparity, there are multiple characteristics that are modifiable by public policies. In particular, providing better insurance coverage and improving educational opportunities to Hispanics could reduce the disparity by 5.4 percentage points, or about $25 \%$.

In order to test the robustness of these results, we repeat the analysis for two additional diseases, high cholesterol and hypertension, but only report the aggregate effects. ${ }^{14}$ Again, each regression is restricted to a sample that self-reports having the disease and the dependent variable

\footnotetext{
${ }^{14}$ Full logit estimates and decomposition results are available upon request from the authors.
} 
is a binary indicator for receipt of a specific class of drugs for that disease. Using indicator variables of race/ethnicity in the pooled regression, disparities are found to exist in the use of statins for high cholesterol and hypertensive drugs for high blood pressure. In the high cholesterol sample, blacks have a 4.7 percentage point lower probability of receiving a statin than whites and the difference for Hispanics 6.6 percentage points lower compared to whites. The result is statistically significant at the $5 \%$ level for Hispanics. In contrast, for hypertensive drugs, blacks have a 12.8 percentage point lower probability of receiving a hypertensive drug than whites, while Hispanics use fewer hypertensive drugs than whites (3.6 percentage points). This result is statistically significant at the $1 \%$ level for blacks but was not significant for Hispanics.

The aggregate decomposition results for all three samples are reported in Table 5. Similar to the use of antidepressants, the disparity between blacks and whites in the use of statins for high cholesterol is almost entirely explained by the coefficients effect. In fact, if blacks had the same coefficients as whites, blacks would use more statins than whites, while if blacks had the same characteristics as whites the disparity would get larger. Both results are statistically insignificant. In the case of Hispanics, both the characteristics and coefficients effects are statistically significant. Of the 14.3 percent disparity between Hispanics and whites in the use of statins for high cholesterol, $46.7 \%$ is explained by the characteristics effect, and the remaining $53.3 \%$ is explained by the coefficients effect.

For the use of hypertensive drugs for high blood pressure, the majority of the disparity between blacks and whites is attributed to the coefficients effect (86.6\%). However, unlike the other two treatments, blacks also have a statistically significant aggregate characteristics effect. If blacks with self-reported high blood pressure had the same characteristics as whites with self- 
reported high blood pressure, the disparity is reduced by 2.0 percentage points. The disparity between Hispanics and whites is approximately equally split between the aggregate characteristics and coefficients effects, but neither effect is statistically significant.

\section{<INSERT TABLE 5>}

\section{Discussion and Conclusion}

Advancing our understanding of the factors that drive racial/ethnic disparities and how these factors could be different depending on the race/ethnicity of individual and the disease being treated can help in devising appropriate public policies. Our decomposition analysis suggests that blacks are largely different from whites through the coefficients effect once they are diagnosed with a medical condition. This means that public policies that attempt to reduce the disparities between whites and blacks in the use of drug therapy should focus on why blacks with characteristics similar to whites behave differently. In the analysis of antidepressant use, the differences in coefficient estimates for the education and health-related variables compared to whites are important in determining the source of the disparity. Since these differences most likely arise because of modifiable behaviors, it is important for policy-maker and researchers to understand and ask questions, such as, why do depressed blacks with higher levels of education have different rates of use of antidepressants than depressed whites with similar education?

Some of the difference between white and black antidepressant use is reflected in cultural differences and social stigma related to depression (Givens et al, 2007). ${ }^{15}$ Blacks may be more reliant on informal support networks or other alternative support mechanisms, such as ministers, reducing the likelihood of using antidepressant therapy as a first option for treatment compared

\footnotetext{
${ }^{15}$ For example, Akerlof and Kranton (2000) have examined the effect of the experience of widespread and substantial discrimination on group identity and behavior.
} 
to other racial/ethnic groups (Taylor and Chatters, 1991; Taylor et al, 1996). Another possible reason these disparities in receipt of medical care exist, particularly among blacks, could be due to distrust of physicians and their general perception of physicians. ${ }^{16}$ These perceptions could have caused blacks to distrust the medical system and exacerbated racial/ethnic differences in the perceived efficacy of prescription drugs. This means that attempts to reduce disparities in the use of drug therapy between white and blacks needs to focus on the education of the risks of leaving medical conditions untreated and to break down barriers, such as trust in physicians, that make minorities hesitant of accepting the efficacies of drug treatment.

In contrast, the disparity between Hispanics and whites is rooted in both characteristics and coefficients effects. In particular one-third to one-half of the disparity between Hispanics and whites is explained by differences in the characteristics effect. The sources of some of the disparity between whites and Hispanics are able to be reduced either through modifying behavior or reducing differences in socio-economic status. For example, Hispanics are younger than whites and younger persons are less likely to take and adhere to prescriptions therapies. Public policy focusing on educating the young about the efficacy of drugs would mitigate the disparity between whites and Hispanics. Besides focusing on demographic differences, Hispanics are less likely to have private insurance and are more likely to be uninsured or on Medicaid. Clearly, this is an access and quality of health insurance issue. In the case of uninsured, disparities could be reduced by expanding incentives for employers to provide insurance or to significantly improve coverage through the expansion of public programs. For those covered by Medicaid, physicians could locate in areas in which it is harder for Medicaid recipients to access them. This could be

\footnotetext{
${ }^{16}$ Doescher et al. (2000) found that minority group members reported less positive perception of physicians than whites while Darity (2003) found that perceptions of racism can have an impact on well-being.
} 
solved by increasing reimbursement or providing other incentives for physicians to locate in primarily Medicaid neighborhoods.

In the development of national health policy, it is critical to understand the factors that attribute to the significant variation in utilization of health care across the races and ethnicities. The Oaxaca-type decomposition for discrete-choice outcomes that analyzes the use of prescription drug therapy not only allows for identification of the existence and size of racial/ethnic disparities, but also identifies what may be the underlying factors that cause the disparity. Further, by using the decomposition for different races and ethnicities, the method identifies how the determinants of disparities could vary for different groups. We find that the disparity between white and blacks in the use of prescription drug therapy can largely be explained by differences in the coefficients effect, while the disparity between whites and Hispanics is split between the coefficients and characteristics effects. A caveat of this study is that although this paper has focused on disparities among whites, blacks and Hispanics, we should be aware that there is also significant heterogeneity within each population. ${ }^{17}$ Further research is needed to determine if the effects found are uniform among all segments of the Hispanic and black populations. However, these results do suggest that the determinants of disparities can be different for specific racial and ethnic groups, and public policy may need to be tailored to the specific group to reduce disparities.

\footnotetext{
${ }^{17}$ In the Hispanic population, Puerto Ricans have been found to experience health disparities while Mexicans have health advantages depending on the health outcome measure (Zsembik and Fennell, 2005). In the black population, Caribbean blacks have been found to have lower rates of treatment for major depressive disorder than African Americans (Williams et al., 2007).
} 


\section{References}

Abowd, J.M., and M. R. Killingsworth. 1984. Do Minority/White Unemployment Differences Really Exist? Journal of Business and Economic Statistics 2: 64-72.

Agency for Healthcare Research and Quality. 2005. 2005 National Healthcare Disparities Report. Rockville, MD: US Department of Health and Human Services.

Akerlof, G. and R. Kranton. 2000. Economics and Identity. Quarterly Journal of Economics CVX: 715-753.

Anderson, N. B., R. A. Bulatao, and B. Cohen, Eds. 2004. Critical Perspectives on Racial and Ethnic Differences in Health in Late Life Washington, DC: The National Academies Press.

Briesacher, B., R. Limcangco, and D. Gaskin. 2004. Racial and ethnic disparities in prescription coverage and medication use. Health Care Financing Review 25: 63-76.

Darity, W. A. 2003. Employment, discrimination, segregation, and health. American Journal of Public Health 93(2): 226-231.

Doescher, M. P, B. G. Saver, P. Franks, and K. Fiscella. 2000. Racial and ethnic disparities in perception of physician style and trust. Archives of Family Medicine 9:1156-63.

Fairlie, R. W. 2005. An Extension of the Blinder-Oaxaca Decomposition Technique to Logit and Probit Models. Journal of Economic and Social Measurement 30: 305-316.

Gonález, H. M., T. Croghan, B. West, D. Williams, R. Nesse, W. Tarraf, R. Taylor, L. Hinton, H. Neighbors, J. Jackson. 2008. Antidepressant Use in Black And White Populations in the United States. Psychiatric Services 59(10): 1131-8.

Givens, J. L., I. R. Katz, S. Bellamy, and W. C. Holmes. 2007. Stigma and the acceptability of depression treatment among African Americans and whites. Journal of General Internal Medicine 22: 1292-1297.

Ham, J. C., J. Svejnar, and K. Terrell. 1998. Unemployment and the Social Safety Net During Transitions to a Market Economy: Evidence from the Czech and Slovak Republics. American Economic Review 88: 1117-1142.

Han, E., and G. G. Liu. 2005. Racial disparities in prescription drug use for mental illness among population in US. The Journal of Mental Health Policy and Economics 8: 131-43.

Hummer, R. A., D. A. Powers, S. G. Pullum, G. L. Gossman, and W. P Frisbie. 2007. Paradox Found (Again): Infant Mortality among the Mexican-Origin Population in the United States. Demography 44(3): 441-57 
Jacobson, J. O., P. Robinson, and R. N. Bluthenthal. 2007. A multilevel decomposition approach to estimate the role of program location and neighborhood disadvantage in racial disparities in alcohol treatment completion. Social Science \& Medicine 64: 462-76.

Jha, A. K., E. S. Fisher, Z. Li, E. J. Orav, and A. M. Epstein. 2005. Racial trends in the use of major procedures among the elderly. New England Journal of Medicine 353:683-691.

Kaiser Family Foundation. 2007. Key Facts: Race, Ethnicity and Medical Care. Washington, DC.

Markides, K. S., and K. Eschbach. 2005. Aging, Migration, and Mortality: Current Status of Research on the Hispanic Paradox. Journals of Gerontology: SERIES B 60B (Special Issue B): 68-75.

Mayberry, R. M., F. Mili, and E. Ofili. 2000. Racial and ethnic differences in access to medical care. Medical Care Research and Review 57: 108-145.

Myers, H. F., I. Lesser, N. Rodriguez, C. B. Mira, W. Hwang, C. Camp, D. Anderson, L. Erickson, and M. Wohl. 2002. Ethnic Differences in Clinical Presentation of Depression in Adult Women. Cultural Diversity and Ethnic Minority Psychology 8(2): 138-56.

National Research Council. 2004. Understanding Racial and Ethnic Disparities in Health in Late Life: A Research Agenda. Panel on Race, Ethnicity, and Health in Later Life. Rolfolfo A. Bulatao and Norman B. Anderson, Eds. Committee on Population, Division of Behavioral and Social Sciences and Education. Washington, DC: The National Academies Press.

Oaxaca, R. 1973. "Male-Female Wage Differentials in Urban Labor Markets.” International Economic Review 14: 693-709.

Oaxaca, R., and M. R. Ransom. 1999. "Identification in Detailed Wage Decompositions.” Review of Economics and Statistics 81: 154-157.

Palloni, A., and E. Arias. 2004. Paradox Lost: Explaining the Hispanic Adult Morality Advantage. Demography 41(3): 385-415.

Palloni, A., and J. Morenoff. 2001. Interpreting the Paradoxical in the Hispanic Paradox: Demographic and Epidemiological Approaches. Annals of the New York Academy of Sciences 954:140-74.

Park, T. A., and L. Lohr. 2008. "A Oaxaca-Blinder Decomposition for Count Data Models." Applied Economics Letters, 1-5, iFirst.

Powers, D. A., and Yun M-S. 2009. "Multivariate Decomposition for Hazard Rate Models."Sociological Methodology 39: 233-263. 
Pylypchuk, Y. and T. M. Selden. 2008. A discrete choice decomposition analysis of racial and ethnic differences in children's health insurance coverage. Journal of Health Economics 27: 1109-1128.

Schneider, E., A. Zaslavsky, and A. Epstein. 2002. Racial disparities in the quality of care for enrollees in Medicare managed care. Journal of the American Medical Association 287: 12881294.

Schore, J., R. Brown, and B. Lavin. 2004. Racial disparities in prescription drug use among dually eligible beneficiaries. Health Care Financing Review 25: 77-90.

Smedley, B. D., A. Y. Stith, and A. R. Nelson, Eds. 2003. Unequal Treatment: Confronting Racial and Ethic Disparities in Health Care Washington, DC: The National Academies Press.

Taylor, R.J., and L. M. Chatters. 1991. Extended family networks of older black adults. Journal of Gerontology 46: S210-17.

Taylor, R. J., C. B. Hardison, and L. M. Chatters. 1996. Kin and non-kin as sources of informal assistance. In Neighbors, H. W. and J. S. Jackson, eds. Mental Health in Black America. Newbury Park, CA: Sage Publishers.

Thomasson, M. A. 2006. Racial differences in health insurance coverage and medical expenditures in the United States: A Historical Perspective. Social Science History 30: 529-550.

Trivedi, A. N., A. M. Zaslavsky, E. C. Schneider, and J. Z. Ayanian. 2005. Trends in the quality of care and racial disparities in Medicare managed care. New England Journal of Medicine 353: 692-700.

Üstün, T. B., J. L. Ayuso-Mateos, S. Chatterji, et al. 2004. Global burden of depressive disorders in the year 2000. British Journal of Psychiatry 184: 386-92.

Weinick, R. M., S. H. Zuvekas, and J. W. Cohen. Racial and ethnic differences in access to and use of health care services. Medical Care Research and Review 57: 36-54.

Williams, D. R., H. M. González, H. Neighbors, R. Nesse, J. M. Abelson, J. Sweetman, and J.S. Jackson. 2007. Prevalence and Distribution of Major Depressive Disorder in African American, Caribbean Blacks, and Non-Hispanic Whites. Archives in General Psychiatry 64:305-15.

Yun, M-S. 2004. Decomposition Differences in the First Moment. Economics Letters 82: 273278.

Yun, M-S. 2005a. Hypothesis Tests when Decomposing Differences in the First Moment. Journal of Economic and Social Measurement 30: 295-304.

Yun, M-S. 2005b. A Simple Solution to the Identification Problem in Detailed Wage Decomposition. Economic Inquiry 43: 766-772. 
Yun, M-S. 2008. Identification Problem and Detailed Oaxaca Decomposition: A General Solution and Inference. Journal of Economic and Social Measurement 33: 27-38.

Zambrana, R. E., and O. Carter-Pokras. 2001. Health Data Issues for Hispanics: Implications for Public Health Research. Journal of the Health Care for the Poor and Underserved 12(1): 20-34.

Zwellweger, M. J., R. H. Osterwalder, W. Langewitz, and M. E. Pfisterer. 2004. Coronary artery disease and depression. European Heart Journal 25(1): 3-9.

Zuvekas, S. H. and G. S. Taliaferro. 2003. Pathways to access: Health insurance, the health care delivery system, and racial/ethnic disparities, 1996-1999. Health Affairs 22: 139-53. 
Table 1: Descriptive Statistics: Pharmacologic Use, By Race/Ethnicity

\begin{tabular}{|c|c|c|c|c|c|}
\hline & \multicolumn{3}{|c|}{ Pharmacologic Use } & \multicolumn{2}{|c|}{$\begin{array}{l}\text { Difference compared to } \\
\text { Whites }\end{array}$} \\
\hline & Whites & Blacks & Hispanics & Blacks & Hispanics \\
\hline $\begin{array}{l}\text { Treated with Antidepressant } \\
\text { Conditional on Depression Diagnosis }\end{array}$ & $68.10 \%$ & $51.39 \%$ & $46.57 \%$ & $16.71 \%$ & $21.53 \%$ \\
\hline $\begin{array}{l}\text { Treated with Statin Conditional on High } \\
\text { Cholestrol Diagnosis }\end{array}$ & $82.30 \%$ & $78.26 \%$ & $68.03 \%$ & $4.04 \%$ & $14.27 \%$ \\
\hline $\begin{array}{l}\text { Treated with Hypertensive Drug } \\
\text { Conditional on Hypertension Diagnosis }\end{array}$ & $66.15 \%$ & $51.50 \%$ & $61.26 \%$ & $14.65 \%$ & $4.89 \%$ \\
\hline
\end{tabular}


Table 2: Descriptive Statistics: Depression Sample, By Race/Ethnicity

\begin{tabular}{|c|c|c|c|c|c|c|}
\hline \multirow[b]{2}{*}{ Variables } & \multicolumn{2}{|c|}{ Whites } & \multicolumn{2}{|c|}{ Blacks } & \multicolumn{2}{|c|}{ Hispanics } \\
\hline & Mean & $\begin{array}{l}\text { Standard } \\
\text { Deviation }\end{array}$ & Mean & $\begin{array}{l}\text { Standard } \\
\text { Deviation }\end{array}$ & Mean & $\begin{array}{l}\text { Standard } \\
\text { Deviation }\end{array}$ \\
\hline \multicolumn{7}{|l|}{ Demographic Variables } \\
\hline Age & 48.102 & 15.691 & 45.199 & 14.013 & 44.173 & 15.396 \\
\hline Age Squared (100's) & 25.599 & 15.752 & 22.384 & 13.363 & 21.876 & 14.571 \\
\hline Male & 0.314 & 0.464 & 0.231 & 0.423 & 0.269 & 0.444 \\
\hline Married & 0.509 & 0.500 & 0.245 & 0.431 & 0.475 & 0.500 \\
\hline \multicolumn{7}{|l|}{ Education Variables } \\
\hline Less than High School & 0.160 & 0.367 & 0.278 & 0.449 & 0.534 & 0.500 \\
\hline College Education & 0.203 & 0.402 & 0.120 & 0.326 & 0.060 & 0.237 \\
\hline \multicolumn{7}{|l|}{ Income } \\
\hline Income (1,000's) & 25.376 & 26.482 & 15.765 & 20.077 & 12.644 & 15.521 \\
\hline \multicolumn{7}{|l|}{ Obesity } \\
\hline Overweight BMI & 0.310 & 0.462 & 0.269 & 0.444 & 0.352 & 0.478 \\
\hline Obese BMI & 0.330 & 0.470 & 0.449 & 0.499 & 0.340 & 0.475 \\
\hline \multicolumn{7}{|l|}{ Health Variables } \\
\hline Report Poor Physical Health & 0.319 & 0.466 & 0.444 & 0.498 & 0.403 & 0.491 \\
\hline Report Poor Mental Health & 0.060 & 0.238 & 0.111 & 0.315 & 0.072 & 0.258 \\
\hline \# Heart Disease Conditions & 0.481 & 0.772 & 0.556 & 0.745 & 0.367 & 0.633 \\
\hline Medicare Insurance & 0.233 & 0.423 & 0.171 & 0.378 & 0.143 & 0.351 \\
\hline Medicaid Insurance & 0.169 & 0.375 & 0.449 & 0.499 & 0.355 & 0.479 \\
\hline Private Insurance & 0.689 & 0.463 & 0.394 & 0.490 & 0.367 & 0.483 \\
\hline \multicolumn{7}{|l|}{ Region Variables } \\
\hline Northeast & 0.160 & 0.367 & 0.148 & 0.356 & 0.152 & 0.360 \\
\hline Midwest & 0.264 & 0.441 & 0.222 & 0.417 & 0.081 & 0.273 \\
\hline South & 0.359 & 0.480 & 0.519 & 0.501 & 0.322 & 0.468 \\
\hline West & 0.216 & 0.412 & 0.111 & 0.315 & 0.445 & 0.498 \\
\hline MSA & 0.731 & 0.444 & 0.801 & 0.400 & 0.899 & 0.302 \\
\hline Sample Size & 1483 & & 216 & & 335 & \\
\hline
\end{tabular}

The sample is restricted to adult individuals that self-report being told by a doctor they are depressed. 
Table 3: Logit Regression Results: Depression Sample

\begin{tabular}{|c|c|c|c|c|c|c|c|c|}
\hline & \multicolumn{2}{|c|}{ Pooled } & \multicolumn{2}{|l|}{ Whites } & \multicolumn{2}{|l|}{ Blacks } & \multicolumn{2}{|c|}{ Hispanics } \\
\hline & \multicolumn{2}{|c|}{ Marginal } & \multicolumn{2}{|r|}{ Marginal } & \multicolumn{2}{|c|}{ Marginal } & \multicolumn{2}{|c|}{ Marginal } \\
\hline & Coefficient & Effect & Coefficient & Effect & Coefficient & Effect & Coefficient & Effect \\
\hline Intercept & $\begin{array}{l}-1.562^{* * *} \\
(0.470)\end{array}$ & N.M. & $\begin{array}{l}-1.551^{\text {*** }} \\
(0.558)\end{array}$ & N.M. & $\begin{array}{l}-4.709^{* * *} \\
(1.688)\end{array}$ & N.M. & $\begin{array}{r}-1.972 \\
(1.271)\end{array}$ & N.M. \\
\hline \multicolumn{9}{|l|}{ Demographic Variables } \\
\hline Age & $\begin{array}{l}0.099^{* * *} \\
(0.019)\end{array}$ & $\begin{array}{l}0.023 \text { *** } \\
(0.004)\end{array}$ & $\begin{array}{l}0.094^{* * *} \\
(0.023)\end{array}$ & $\begin{array}{l}0.020 \text { *** } \\
(0.005)\end{array}$ & $\begin{array}{l}0.194^{\text {***}} \\
(0.067)\end{array}$ & $\begin{array}{l}0.048^{\text {*** }} \\
(0.017)\end{array}$ & $\begin{array}{l}0.104 \text { ** } \\
(0.050)\end{array}$ & $\begin{array}{l}0.026 \text { ** } \\
(0.012)\end{array}$ \\
\hline Age Squared (100's) & $\begin{array}{l}-0.095^{* * *} \\
(0.020)\end{array}$ & $\begin{array}{l}-0.022 \\
(0.005)\end{array}$ & $\begin{array}{l}-0.086 \text { *** } \\
(0.024)\end{array}$ & $\begin{array}{l}-0.018^{\text {*** }} \\
(0.005)\end{array}$ & $\begin{array}{l}-0.210^{* * *} \\
(0.074)\end{array}$ & $\begin{array}{l}-0.052 \text { *** } \\
(0.018)\end{array}$ & $\begin{array}{l}-0.107 \text { * } \\
(0.055)\end{array}$ & $\begin{array}{l}-0.027 \text { * } \\
(0.014)\end{array}$ \\
\hline Male & $\begin{array}{l}-0.390^{* * *} \\
(0.108)\end{array}$ & $\begin{array}{l}-0.0922^{\text {*** }} \\
(0.026)\end{array}$ & $\begin{array}{l}-0.405^{* * *} \\
(0.126)\end{array}$ & $\begin{array}{l}-0.089 \text { *** } \\
(0.028)\end{array}$ & $\begin{array}{r}0.367 \\
(0.381)\end{array}$ & $\begin{array}{r}0.091 \\
(0.092)\end{array}$ & $\begin{array}{l}-0.600 \text { ** } \\
(0.287)\end{array}$ & $\begin{array}{l}-0.146 \text { ** } \\
(0.068)\end{array}$ \\
\hline Married & $\begin{array}{r}0.077 \\
(0.105)\end{array}$ & $\begin{array}{r}0.018 \\
(0.024)\end{array}$ & $\begin{array}{r}0.065 \\
(0.125)\end{array}$ & $\begin{array}{r}0.014 \\
(0.027)\end{array}$ & $\begin{array}{l}-0.277 \\
(0.377)\end{array}$ & $\begin{array}{l}-0.069 \\
(0.094)\end{array}$ & $\begin{array}{r}0.222 \\
(0.266)\end{array}$ & $\begin{array}{r}0.055 \\
(0.066)\end{array}$ \\
\hline \multicolumn{9}{|l|}{ Education Variables } \\
\hline Less than High School & $\begin{array}{l}-0.253^{\text {** }} \\
(0.128)\end{array}$ & $\begin{array}{l}-0.059 \text { * } \\
(0.030)\end{array}$ & $\begin{array}{r}-0.183 \\
(0.168)\end{array}$ & $\begin{array}{r}-0.040 \\
(0.037)\end{array}$ & $\begin{array}{r}0.143 \\
(0.393)\end{array}$ & $\begin{array}{r}0.035 \\
(0.097)\end{array}$ & $\begin{array}{l}-0.571 \\
(0.270)\end{array}$ & $\begin{array}{l}-0.141 \\
(0.066)\end{array}$ \\
\hline College Education & $\begin{array}{l}0.306 \text { ** } \\
(0.146)\end{array}$ & $\begin{array}{l}0.068 \text { ** } \\
(0.031)\end{array}$ & $\begin{array}{l}0.422 \text { *** } \\
(0.164)\end{array}$ & $\begin{array}{l}0.085^{* * *} \\
(0.031)\end{array}$ & $\begin{array}{l}-1.415^{\text {*** }} \\
(0.561)\end{array}$ & $\begin{array}{l}-0.326^{\text {*** }} \\
(0.108)\end{array}$ & $\begin{array}{r}0.319 \\
(0.533)\end{array}$ & $\begin{array}{r}0.080 \\
(0.132)\end{array}$ \\
\hline \multicolumn{9}{|l|}{ Income } \\
\hline Income (1,000's) & $\begin{array}{l}-0.002 \\
(0.002)\end{array}$ & $\begin{array}{r}0.000 \\
(0.001)\end{array}$ & $\begin{array}{l}-0.003 \\
(0.003)\end{array}$ & $\begin{array}{l}-0.001 \\
(0.001)\end{array}$ & $\begin{array}{c}0.016 \text { * } \\
(0.009)\end{array}$ & $\begin{array}{r}0.004 \text { * } \\
(0.002)\end{array}$ & $\begin{array}{r}-0.006 \\
(0.009)\end{array}$ & $\begin{array}{l}-0.001 \\
(0.002)\end{array}$ \\
\hline \multicolumn{9}{|l|}{ Obesity } \\
\hline Overweight BMI & $\begin{array}{r}0.121 \\
(0.120)\end{array}$ & $\begin{array}{r}0.028 \\
(0.027)\end{array}$ & $\begin{array}{r}0.148 \\
(0.142)\end{array}$ & $\begin{array}{r}0.031 \\
(0.030)\end{array}$ & $\begin{array}{r}0.054 \\
(0.429)\end{array}$ & $\begin{array}{r}0.014 \\
(0.107)\end{array}$ & $\begin{array}{r}0.071 \\
(0.299)\end{array}$ & $\begin{array}{r}0.018 \\
(0.074)\end{array}$ \\
\hline Obese BMI & $\begin{array}{l}0.256 \text { ** } \\
(0.123)\end{array}$ & $\begin{array}{c}0.058 \text { ** } \\
(0.028)\end{array}$ & $\begin{array}{r}0.227 \\
(0.147)\end{array}$ & $\begin{array}{r}0.048 \\
(0.030)\end{array}$ & $\begin{array}{c}0.822 \text { ** } \\
(0.397)\end{array}$ & $\begin{array}{l}0.202 \text { ** } \\
(0.094)\end{array}$ & $\begin{array}{r}0.261 \\
(0.302)\end{array}$ & $\begin{array}{r}0.065 \\
(0.075)\end{array}$ \\
\hline \multicolumn{9}{|l|}{ Health Variables } \\
\hline Report Poor Physical Health & $\begin{array}{r}0.153 \\
(0.116)\end{array}$ & $\begin{array}{r}0.035 \\
(0.026)\end{array}$ & $\begin{array}{r}0.123 \\
(0.142)\end{array}$ & $\begin{array}{r}0.026 \\
(0.030)\end{array}$ & $\begin{array}{l}-0.159 \\
(0.351)\end{array}$ & $\begin{array}{r}-0.040 \\
(0.087)\end{array}$ & $\begin{array}{c}0.533 \text { * } \\
(0.276)\end{array}$ & $\begin{array}{c}0.132 \text { ** } \\
(0.068)\end{array}$ \\
\hline Report Poor Mental Health & $\begin{array}{l}0.4744^{* *} \\
(0.213)\end{array}$ & $\begin{array}{l}0.102 \text { ** } \\
(0.042)\end{array}$ & $\begin{array}{r}0.137 \\
(0.259)\end{array}$ & $\begin{array}{r}0.029 \\
(0.053)\end{array}$ & $\begin{array}{r}0.577 \\
(0.518)\end{array}$ & $\begin{array}{r}0.140 \\
(0.119)\end{array}$ & $\begin{array}{l}1.393 \text { ** } \\
(0.569)\end{array}$ & $\begin{array}{c}0.320 \\
(0.106)\end{array}$ \\
\hline \# Heart Disease Conditions & $\begin{array}{r}-0.014 \\
(0.077)\end{array}$ & $\begin{array}{r}-0.003 \\
(0.018)\end{array}$ & $\begin{array}{r}0.022 \\
(0.090)\end{array}$ & $\begin{array}{r}0.005 \\
(0.019)\end{array}$ & $\begin{array}{r}-0.062 \\
(0.266)\end{array}$ & $\begin{array}{l}-0.015 \\
(0.066)\end{array}$ & $\begin{array}{r}0.036 \\
(0.221)\end{array}$ & $\begin{array}{r}0.009 \\
(0.055)\end{array}$ \\
\hline Medicare Insurance & $\begin{array}{l}0.115^{\text {*** }} \\
(0.187)\end{array}$ & $\begin{array}{l}0.115^{\text {*** }} \\
(0.039)\end{array}$ & $\begin{array}{r}0.263 \\
(0.220)\end{array}$ & $\begin{array}{r}0.054 \\
(0.044)\end{array}$ & $\begin{array}{l}2.634^{\text {***}} \\
(0.699)\end{array}$ & $\begin{array}{l}0.493^{\text {***}} \\
(0.077)\end{array}$ & $\begin{array}{r}0.598 \\
(0.511)\end{array}$ & $\begin{array}{r}0.148 \\
(0.124)\end{array}$ \\
\hline Medicaid Insurance & $\begin{array}{r}0.154 \\
(0.146)\end{array}$ & $\begin{array}{r}0.035 \\
(0.033)\end{array}$ & $\begin{array}{r}0.102 \\
(0.189)\end{array}$ & $\begin{array}{r}0.022 \\
(0.039)\end{array}$ & $\begin{array}{r}0.334 \\
(0.432)\end{array}$ & $\begin{array}{r}0.083 \\
(0.107)\end{array}$ & $\begin{array}{r}0.209 \\
(0.315)\end{array}$ & $\begin{array}{r}0.052 \\
(0.079)\end{array}$ \\
\hline Private Insurance & $\begin{array}{l}0.341^{\star \star *} \\
(0.130)\end{array}$ & $\begin{array}{l}0.079 \text { *** } \\
(0.030)\end{array}$ & $\begin{array}{l}0.377^{\text {** }} \\
(0.156)\end{array}$ & $\begin{array}{l}0.082 \text { ** } \\
(0.035)\end{array}$ & $\begin{array}{r}0.348 \\
(0.474)\end{array}$ & $\begin{array}{r}0.086 \\
(0.117)\end{array}$ & $\begin{array}{r}0.370 \\
(0.302)\end{array}$ & $\begin{array}{r}0.092 \\
(0.075)\end{array}$ \\
\hline Region Variables & & & & & & & & \\
\hline Midwest & $\begin{array}{l}-0.287 \text { * } \\
(0.163)\end{array}$ & $\begin{array}{l}-0.067 \text { * } \\
(0.039)\end{array}$ & $\begin{array}{l}-0.335 \text { * } \\
(0.188)\end{array}$ & $\begin{array}{l}-0.073 \text { * } \\
(0.042)\end{array}$ & $\begin{array}{r}-0.251 \\
(0.521)\end{array}$ & $\begin{array}{r}-0.063 \\
(0.130)\end{array}$ & $\begin{array}{r}-0.081 \\
(0.549)\end{array}$ & $\begin{array}{l}-0.020 \\
(0.136)\end{array}$ \\
\hline South & $\begin{array}{r}0.081 \\
(0.153)\end{array}$ & $\begin{array}{r}0.019 \\
(0.035)\end{array}$ & $\begin{array}{r}0.079 \\
(0.184)\end{array}$ & $\begin{array}{r}0.017 \\
(0.039)\end{array}$ & $\begin{array}{r}0.380 \\
(0.490)\end{array}$ & $\begin{array}{r}0.095 \\
(0.121)\end{array}$ & $\begin{array}{r}0.124 \\
(0.402)\end{array}$ & $\begin{array}{r}0.031 \\
(0.100)\end{array}$ \\
\hline West & $\begin{array}{l}-0.414 \\
(0.158)\end{array}$ & $\begin{array}{l}-0.098 \text { ** } \\
(0.038)\end{array}$ & $\begin{array}{l}-0.424 \text { ** } \\
(0.192)\end{array}$ & $\begin{array}{l}-0.094 \\
(0.044)\end{array}$ & $\begin{array}{r}0.364 \\
(0.611)\end{array}$ & $\begin{array}{r}0.089 \\
(0.147)\end{array}$ & $\begin{array}{r}-0.452 \\
(0.374)\end{array}$ & $\begin{array}{r}-0.112 \\
(0.092)\end{array}$ \\
\hline MSA & $\begin{array}{l}-0.387^{* * *} \\
(0.124)\end{array}$ & $\begin{array}{l}-0.086 \text { *** } \\
(0.027)\end{array}$ & $\begin{array}{l}-0.335 \text { ** } \\
(0.139)\end{array}$ & $\begin{array}{l}-0.069 \text { ** } \\
(0.028)\end{array}$ & $\begin{array}{l}-0.799 \text { * } \\
(0.437)\end{array}$ & $\begin{array}{l}-0.191 \\
(0.098)\end{array}$ & $\begin{array}{r}-0.649 \\
(0.418)\end{array}$ & $\begin{array}{r}-0.160 \\
(0.100)\end{array}$ \\
\hline Race & & & & & & & & \\
\hline Black & $\begin{array}{l}-0.771^{\text {*** }} \\
(0.162)\end{array}$ & $\begin{array}{l}-0.187^{\text {***}} \\
(0.040)\end{array}$ & & & & & & \\
\hline Hispanic & $\begin{array}{l}-0.619 \\
(0.143)\end{array}$ & $\begin{array}{l}-0.149 \text { *** } \\
(0.035)\end{array}$ & & & & & & \\
\hline Sample Size & 2034 & & 1483 & & 216 & & 335 & \\
\hline Pseudo R-Squared & 0.077 & & 0.053 & & 0.138 & & 0.104 & \\
\hline
\end{tabular}

The sample is restricted to adult individuals that self-report being told by a doctor they are depressed.

${ }^{* \star *},{ }^{* *},{ }^{*}$ denote significance at the $1 \%, 5 \%$, and $10 \%$ levels, respectively. 
Table 4: Decomposition of Difference in Treatment of Depression with Antidepressants: Depression Sample

\begin{tabular}{|c|c|c|c|c|c|c|c|c|}
\hline & \multicolumn{4}{|c|}{ Difference Between Whites and Blacks } & \multicolumn{4}{|c|}{ Difference Between Whites and Hispanics } \\
\hline & \multicolumn{2}{|c|}{ Characteristics Effect } & \multicolumn{2}{|c|}{ Coefficients Effect } & \multicolumn{2}{|c|}{ Characteristics Effect } & \multicolumn{2}{|c|}{ Coefficients Effect } \\
\hline & Estimate & Share & Estimate & Share & Estimate & Share & Estimate & Share \\
\hline Aggregate Effect & $\begin{array}{r}0.004 \\
(0.013)\end{array}$ & 2.52 & $\begin{array}{l}0.163^{* * *} \\
(0.035)\end{array}$ & 97.48 & $\begin{array}{l}0.070^{* * *} \\
(0.019)\end{array}$ & 32.69 & $\begin{array}{l}0.145^{\text {*** }} \\
(0.034)\end{array}$ & 67.31 \\
\hline Sub-Aggregate Effects & & & & & & & & \\
\hline Demographic Variables & $\begin{array}{l}-0.004 \\
(0.010)\end{array}$ & -2.41 & $\begin{array}{l}-0.378 \\
(0.369)\end{array}$ & -226.23 & $\begin{array}{c}0.008 \text { * } \\
(0.005)\end{array}$ & 3.54 & $\begin{array}{l}-0.001 \\
(0.272)\end{array}$ & -0.53 \\
\hline Education Variables & $\begin{array}{r}0.013 \\
(0.009)\end{array}$ & 7.76 & $\begin{array}{l}-0.089^{* * *} \\
(0.031)\end{array}$ & -53.09 & $\begin{array}{c}0.027 \\
(0.014)\end{array}$ * & 12.70 & $\begin{array}{r}0.012 \\
(0.036)\end{array}$ & 5.41 \\
\hline Income & $\begin{array}{l}-0.006 \\
(0.007)\end{array}$ & -3.70 & $\begin{array}{l}-0.069 \text { * } \\
(0.037)\end{array}$ & -41.38 & $\begin{array}{l}-0.008 \\
(0.007)\end{array}$ & -3.51 & $\begin{array}{r}0.009 \\
(0.029)\end{array}$ & 4.31 \\
\hline Obesity & $\begin{array}{r}-0.010 \\
(0.009)\end{array}$ & -6.21 & $\begin{array}{c}0.030 \text { * } \\
(0.066)\end{array}$ & 18.09 & $\begin{array}{l}-0.004 \\
(0.004)\end{array}$ & -1.78 & $\begin{array}{l}0.134 \text { ** } \\
(0.066)\end{array}$ & 62.26 \\
\hline Health Variables & $\begin{array}{r}0.023 \\
(0.014)\end{array}$ & 13.65 & $\begin{array}{l}0.188^{* * *} \\
(0.069)\end{array}$ & 112.19 & $\begin{array}{l}0.027^{* *} \\
(0.012)\end{array}$ & 12.42 & $\begin{array}{r}0.031 \\
(0.049)\end{array}$ & 14.51 \\
\hline Region Variables & $\begin{array}{l}-0.011 \\
(0.009)\end{array}$ & -6.57 & $\begin{array}{r}0.041 \\
(0.048)\end{array}$ & 24.27 & $\begin{array}{l}0.020 \text { ** } \\
(0.008)\end{array}$ & 9.33 & $\begin{array}{r}0.040 \\
(0.049)\end{array}$ & 18.48 \\
\hline Intercept & 0.000 & 0 & $\begin{array}{r}0.441 \\
(0.361)\end{array}$ & 263.63 & 0.000 & 0 & $\begin{array}{r}-0.080 \\
(0.279)\end{array}$ & -37.12 \\
\hline
\end{tabular}

Notes: The sample is restricted to adult individuals that self-report being told by a doctor they are depressed. Estimate is calculated as the amount of the difference in treatment with antidepressants between two racial/ethnic groups that can be explained by differences in the characteristics or coefficient of both groups. The share refers to the proportion of the difference explained by estimate.

***, ${ }^{* *},{ }^{*}$ denote significance at the $1 \%, 5 \%$, and $10 \%$ levels, respectively. 
Table 5: Aggregate Effect of Decomposition of Difference in Treatment: All Samples

Difference Between Whites and Blacks

Characteristics Effect

Coefficients Effect

Share

Characteristics Effect Coefficients Effect

Estimate Share Estimate Share

Treated with Antidepressant Conditional on Depression Diagnosis

Aggregate Effect

$$
0.004
$$

$(0.013)$

2.52

$0.163 * * *$

(0.035)

97.48

$0.070 * * *$

(0.019)

$0.145^{\star \star \star} \quad 67.31$

(0.034)

Treated with Statin Conditional on High Cholestrol Diagnosis

Aggregate Effect

$\begin{array}{lll}-0.005 & -13.59 \quad 0.046\end{array}$

(0.009)

$(0.028)$

113.59

$0.067^{* * *}$

$(0.021)$

46.66

0.076 **

(0.036)

Treated with Hypertensive Drug Conditional on Hypertension Diagnosis

Aggregate Effect

$\begin{array}{llcrr}0.020^{* *} & 13.40 & 0.127^{* * *} & 86.60 & 0.024 \\ (0.010) & & (0.028) & & (0.021)\end{array}$

48.19

0.025

(0.036)

Notes: Samples are restricted to adult individuals that self-report being told by a doctor they have a specific medical condition. A patient is considered treated if they report filling a prescription in the drug class for the medical condition. Each estimate is calculated as the amount of the difference in treatment with reciept of pharmacotherapy between two racial/ethnic groups that can be explained by differences in the characteristics or coefficient of both groups. The share refers to the proportion of the difference explained by estimate.

***, ${ }^{* *},{ }^{*}$ denote significance at the $1 \%, 5 \%$, and $10 \%$ levels, respectively. 